\title{
A State-of-the-art overview
}

\section{Recent development in low friction and wear-resistant coatings and surfaces for high-temperature forming tools}

\author{
Zhenxue Zhang* and Hanshan Dong \\ The University of Birmingham, Edgbaston, Birmingham B15 2TT, UK
}

Received 20 December 2014 / Accepted 13 January 2015

\begin{abstract}
Ever-increasing demand for severe work conditions, high-performance and long-life has been drivers for developing new low-friction and wear resistant coatings and surfaces for high temperature forming tools. This paper provides an overview on the recent development of coatings and modified surfaces to minimise friction and wear between contact surfaces in high-temperature working environments. This overview covers the major progresses in: (1) nanocomposite coatings based on transition metal nitrides and oxides, and the blending with solid lubricants such as silver and (2) multi-layered coatings with different combinations of hard and/or lubricating layers and duplex systems with solid lubricants on textured hard coatings and nanotubes. The challenges and future directions towards long-life and sustainable low-friction and wear-resistant coatings and surfaces for high-temperature forming tools are discussed.
\end{abstract}

Key words: High temperature, Lubrication, Low friction coating, Nanocomposite, Forming tools

\section{Introduction}

The ever increasing demand for quality, flexibility, productivity and environmental performance has introduced new machining and forming technologies, including near net shape production, high speed machining, hard turning, micromanufacturing, dry machining and environmentally conscious machining. The successful implementation of many of these processes demands high performance from the forming tools. The tools have to resist rough conditions, such as the cyclic contact with the rapid-heated materials at temperatures above $1000{ }^{\circ} \mathrm{C}$, abrasive wear by hard particles like scale and oxides, in combination with adhesive wear by high pressure loading [1]. In some forming processes, the severe adhesion between the mould and the working materials becomes a major difficulty for demoulding without applying releasing agents or lubricants. Therefore the production of materials that exhibit low wear rate and low coefficient of friction $(\mathrm{CoF})$ over a wider range of working conditions is a big challenge in modern industrial tribological systems. This technical challenge is relevant not only to metal forming but also to industrial processes including tooling, aerospace parts and assemblies like

\footnotetext{
*e-mail: zhzhxue@yahoo.com
}

propulsion bearing and fasteners and moving assemblies for hypersonic aircraft, missiles and nuclear industries.

In order to improve the performance of the tools, an ideal tool material should combine properties like high hardness, good toughness and chemical stability. Moreover, the material has to cope with thermal loading by being more refractory, or by generating less heat during machining (i.e. reducing both shear and frictional energies), and/or by taking away the generated heat rapidly. With this regard, monolithic tool materials are being replaced by coated tools to enhance their performance. The coatings form a barrier between the tool and the work piece, preventing the tool material from being exposed. This reduces the diffusion rate and lowers the chemically and thermally induced tool wear such as adhesion and oxidation. Coatings can also improve the tools behaviour by altering the coefficient of friction, and increasing the hot hardness, resulting in lower abrasion rate [2].

\section{Potential coatings and solid lubricants for high temperature applications}

Traditionally, thermo-chemical surface treatments, i.e. hardening, nitriding, carbonitriding, are used to improve the wear resistance of forming tools. Hard and corrosion-resistant 
coatings like nitrides and carbides of titanium and chromium (TiN, TiCN, TiAlN and $\mathrm{CrN}$ ) are frequently used to protect the tools and extend their lifetime. These coatings are suitable to avoid galling problems, to prevent forming tool wear and to lower tool maintenance costs. More recently, solid lubricating coatings such as DLC and metal-MoS $\mathrm{M}_{2}$ composites are being used to reduce friction.

Thin films and coatings based on hard and/or solid lubricant materials have been widely used on tribological components to reduce friction, wear and debris generation, and they can be classified into five categories: (1) carbon based materials e.g. graphite, DLCs and nanocrystalline diamond; (2) refractory materials e.g. titanium and chromium based nitrides and carbides, oxides $\left(\mathrm{Al}_{2} \mathrm{O}_{3}\right)$ and cubic boron nitride $(\mathrm{cBN})$, (3) transition metal dichalcogenide compounds $\left(\mathrm{MoS}_{2}\right.$ and $\mathrm{WS}_{2}$ ); (4) polymer (e.g. PTFE) and (5) soft metals like silver, copper, lead, tin, indium and gold [3].

Tin, indium, lead and PTFE have very low melting temperatures which make them inherently unsuitable for high temperature use. On the other hand, silver, copper and gold perform well as solid lubricants at moderately temperature $\left(300-500{ }^{\circ} \mathrm{C}\right)$.

Molybdenum disulphide is the first choice of lubricant in vacuum or dry air environments, but it oxidises rapidly in moist air and acts as an abrasive at room temperature. Furthermore, it is not lubricious at temperatures beyond $350{ }^{\circ} \mathrm{C}$. Compared with $\mathrm{MoS}_{2}, \mathrm{WS}_{2}$ exhibits higher thermal stability and provides a $100{ }^{\circ} \mathrm{C}$ increase in the maximum operating temperature. In a typical $\mathrm{WS}_{2}$ structure, a layer of tungsten atoms is sandwiched between two layers of hexagonally packed sulphur atoms. The bonding between $\mathrm{W}$ and neighbouring $\mathrm{S}$ atoms is covalent, while consecutive layers of $\mathrm{S}$ are held together by weak van der Waals forces, resulting in inter-lamellar mechanical weakness. Thus, under a shearing force, the basal planes slide over one another by intra-crystalline slip and material is transferred to the counterpart rubbing surface, imparting low CoF of 0.02-0.06 in either dry inert gas or in ultrahigh vacuum. Conversely, when sliding in humid air, dangling or unsaturated bonds on the edge of basal planes react with moisture and oxygen in the environment forming $\mathrm{WO}_{3}$, which has a higher $\mathrm{CoF}(>0.15)$ [4].

For high temperature applications $\left(>500{ }^{\circ} \mathrm{C}\right)$, a few oxides $\left(\mathrm{PbO}\right.$ and $\left.\mathrm{B}_{2} \mathrm{O}_{3}\right)$ or fluorides $\left(\mathrm{CaF}_{2}\right.$ and $\left.\mathrm{BaF}_{2}\right)$ are generally used as solid lubricants [5]. However, the shear strength of these materials is relatively high at low temperature, and the incorporation of these phases in a composite generally leads to high coefficient of friction throughout the temperature range used. More recently, oxides of transition metals like vanadium [6], tungsten [7] and molybdenum [8] have attracted much research interests. Double oxides incorporated with noble metals such as silver are particularly interesting solid lubricants [9].

Carbon-based coatings, while providing notable improvements in operating efficiency, are prone to oxidation at operating temperatures exceeding $400{ }^{\circ} \mathrm{C}$. Graphite is an excellent lubricant in dry and humid air but it loses effectiveness in vacuum as it needs condensable vapours (e.g. water) to terminate dangling bonds that are otherwise adhesive in nature [9]. Although diamond coatings, offer several benefits with regard to surface finish, built-up edge, cutting forces and tool life, they do not adhere well to tool substrates, and they can undergo undesirable chemical reactions upon contact with ferrous alloys. Furthermore, their coefficient of thermal expansion is much lower than that of most metals, thus inducing stresses between coating and substrate as the temperature changes.

Ceramic coatings provide thermal stability and higher resistance to abrasive wear but suffer from brittleness and poor bonding to the tool substrate. Cubic $\mathrm{BN}$, which is relatively inert with respect to ferrous metals, is difficult to deposit by PVD (Physical Vapor Deposition) at thicknesses exceeding $300 \mathrm{~nm}$ because of residual stresses that build up in the films [10]. Nanocrystalline $\mathrm{AlMgB}_{14}$ is highly resistive to wear and has a low coefficient of friction, reaching a record value of 0.02 against AISI 52100 steel counter-face in lubricated sliding of $\mathrm{AlMgB}_{14}-\mathrm{TiB}_{2}$ composites [11].

In summary, it is interesting to note that materials that provide lubrication at ambient temperature oxidise at elevated temperatures, while high temperature solid lubricants typically exhibit high friction at room temperature. The drawback of using solid lubricants as monolithic layers is that they are soft, and hence, don't provide enough wear resistance. In addition, no single phase solid lubricant displays a low coefficient of friction in a broad range of environment conditions [12].

Therefore, there has been a continuous driving force to develop better coatings or surface modification solutions to reduce both wear rate and coefficient of friction at high temperature and/or over a wide range of working conditions. Different approaches have been reported extensively, and these coatings can be categorised as follows:

- Nanocomposite coatings based on transition metal nitrides, oxides and the blending of solid lubricants such as noble metal;

- Multi-layer structured coatings and duplex systems with different combinations of hard and/or lubricating coatings.

In this paper, the authors review the recent developments on modified surfaces and coatings with application in a wide temperature range, from room temperature to $1000{ }^{\circ} \mathrm{C}$ and beyond. The working mechanisms and the effect of different coating designs are analysed, in order to find a path to improve the tribological properties especially the reduction of friction during service over a broad range of environmental conditions.

\section{Nanocomposites}

\subsection{Nitrides and their derivatives}

Binary hard coatings based on transition metal nitrides, like $\mathrm{CrN}$ or TiN, are widely used in different industries. These coatings exhibit good bonding to the substrate and offer moderate mechanical and thermal properties with an adequate deposition rate, and they are widely used in different industries. By adding other elements to the base composition, e.g. aluminium, ternary and quaternary coatings are formed (TiAlN, CrAlN and CrAlTiN), with increased hardness and remarkable 


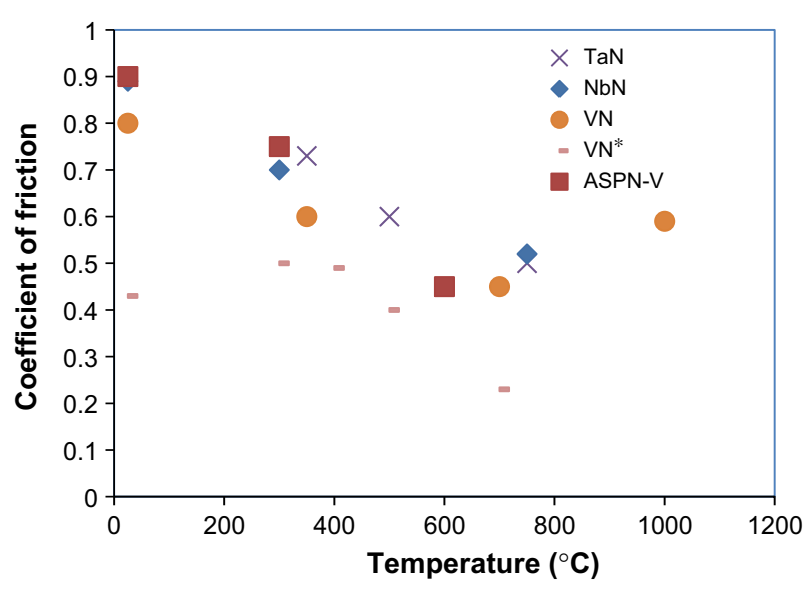

Figure 1. Recorded friction coefficient of a few of nitrides at different temperatures: $\mathrm{NbN}$ [24], TaN [25], VN* [18]/VN [26] and our research of ASPN-V.

improvements in high temperature strength and inertness [13]. TiAlN coatings exhibit high hardness and elasticity as well as high oxidation resistance, which enable such coatings to be employed in higher temperature applications, such as milling and metal forming tools. However the coefficient of friction of TiAlN is between 0.7 and 1.0 which makes the use of lubricants inevitable in most industrial applications. Moreover, the $\mathrm{CoF}$ of most transition metal nitride coatings is fairly high (0.6-0.8) and their tribological effectiveness is insufficient especially at elevated temperatures [14]. Therefore, more element additions like $\mathrm{Si}, \mathrm{Hf}, \mathrm{Nb}, \mathrm{Zr}, \mathrm{V}, \mathrm{B}, \mathrm{Y}$ or $\mathrm{O}$ have been investigated to adjust the tribological performance by varying the content of crystalline and amorphous phases [13, 15]. Nanostructured hard coatings based on nitrides and carbides may contain up to eight different elements [16]. When exposed to air at elevated temperature, some of the nitrides in the coating can easily oxidise. In many cases, the oxidised products are rutile, anatase, and iron oxides, sometimes amorphous and sometimes nano-scale crystalline, which may lower friction, depending on counterpart, contact load and different environmental conditions.

Vanadium has attracted particular attention because $\mathrm{V}_{2} \mathrm{O}_{5}$ platelets formed by thermal oxidation at high temperature (i.e. $500{ }^{\circ} \mathrm{C}$ ) deform plastically to produce a lubricious contact areas between coating and counterparts [17]. In our research, vanadium was successfully deposited on a nickel based superalloy (CM247) surface with a novel active screen plasma nitriding process (ASPN-V), and the CoF of the treated surface against $\mathrm{Al}_{2} \mathrm{O}_{3}$ ball was reduced from above 0.9 at room temperature to lower than 0.4 at $600{ }^{\circ} \mathrm{C}$ as seen in Figure 1. Compared with $\mathrm{TiN}$, the $\mathrm{VN}$ coating deposited by unbalanced magnetron sputtering has a lower $\mathrm{CoF}$ against alumina counterface $(\sim 0.45)$ at RT, which further decreases at temperatures above $400{ }^{\circ} \mathrm{C}$, reaching a value of $0.25-0.27$ at $700{ }^{\circ} \mathrm{C}$. This phenomenon is due to the formation of $\mathrm{V}_{2} \mathrm{O}_{5}$, which acts as a solid lubricant, and the subsequent melting of this phase at temperatures above $600{ }^{\circ} \mathrm{C}$, leading to liquid lubrication (Figure 1) [18]. Vanadium was also incorporated into TiN based coatings via cathodic arc ion-plating, and the $\mathrm{CoF}$ of
(V, Ti) $\mathrm{N}$ coatings against alumina counterface was reduced from 1.08 at room temperature to 0.53 at temperatures above $500{ }^{\circ} \mathrm{C}$ [17]. The incorporation of $\mathrm{V}$ into the TiAlN coatings, either forming a solid solution (Ti-Al-V-N) [19] or a superlattice structure of hard and lubricating layers (TiAlN/VN or TiAlN/TiAlVN) [20], decreased the CoF, especially at elevated temperatures $\left(700{ }^{\circ} \mathrm{C}\right)$, to values as low as 0.18 [21].

Based on a thermodynamic assessment, Becker suggested a metastable solid solution would be synthesized more easily in both the VN-AIN and the VC-AIN systems than in the established TiN-AlN system [22]. However the coatings' response to temperature was not discussed. Vanadium was also used to improve the tribological properties of CrAlN coatings. The CoF of a CrAlVN (20 at.\% V) coating deposited by DC high pulsed power magnetron sputtering (HPPMS) was reduced from 0.6 at room temperature to 0.4 at $800{ }^{\circ} \mathrm{C}$ [23].

However, the low coefficient of friction is strongly dependent on the existence of a liquid Magnéli phase oxide $\left(\mathrm{V}_{2} \mathrm{O}_{5}\right)$ on the surface. The oxygen deficient oxide is only formed between 500 and $700{ }^{\circ} \mathrm{C}$. Consequently, the lubrication effect weakens and diminishes once the oxide is converted into other form of oxide phase. Under $500{ }^{\circ} \mathrm{C}$, the $\mathrm{CoF}$ is persistently high (0.55-0.95).

Similar to VN, hard coatings containing $\mathrm{WN}$ and $\mathrm{MoN}$ have the ability to form lubricious Magnéli phase oxides at elevated temperature. $\mathrm{MoN}$ and $\mathrm{Mo}_{2} \mathrm{~N}$ coatings showed high hardness and relatively low $\mathrm{CoF}$ at low temperatures, but the formation of volatile $\mathrm{MoO}_{3}$ at $500{ }^{\circ} \mathrm{C}$ significantly limited its application in high temperatures [7]. On the other hand, WN coatings demonstrated a higher oxidation threshold at an expense of a higher $\mathrm{CoF}$ [7]. In the case of $\mathrm{NbN}$, the CoF against $\mathrm{Si}_{3} \mathrm{~N}_{4}$ counterface steadily reduced from 0.9 at RT to 0.52 at $750{ }^{\circ} \mathrm{C}$ and $\mathrm{XRD}$ revealed that $\mathrm{NbN}$ coating was completely oxidised into monoclinic $\mathrm{Nb}_{2} \mathrm{O}_{5}$ which has Magneli's phases [24]. The $\mathrm{CoF}$ of TaN against $\mathrm{Si}_{3} \mathrm{~N}_{4}$ counterface displayed a similar trend as seen in Figure 1 [25]. A mixed phase of orthorhombic $\mathrm{Ta}_{2} \mathrm{O}_{5}$ and TaN was identified by XRD after tribotest at $750{ }^{\circ} \mathrm{C}$.

Finally, $\mathrm{AlMgB}_{14}$ is a ceramic alloy that has a low coefficient of sliding friction, reaching a record value of 0.02 against AISI 52100 steel counterface in lubricated $\mathrm{AlMgB}_{14}$ $\mathrm{TiB}_{2}$ composites [10, 27]. Weak, van der Waals-bonded atomic layers of $\mathrm{B}(\mathrm{OH})_{3}$, a product of boron oxide with moisture, tend to slide against each other with little resistance to applied shear stresses which is the primary contribution to low-friction behaviour. Ultrahard, wear-resistant $\mathrm{AlMgB}_{14}$ coatings have been coated on wear-prone components, such as cutting tools and hydraulic pump vanes, using pulsed laser deposition (PLD) to extend their service life by reducing friction [28].

\subsection{Oxide based coatings}

Oxidation plays an important role in the friction mechanism at high temperature in the presence of humid air. Much work has been done to understand the role played by oxides such as $\mathrm{ZnO}, \mathrm{PbO}, \mathrm{NiO}, \mathrm{TiO}_{2-x}, \mathrm{~B}_{2} \mathrm{O}_{3}, \mathrm{Re}_{2} \mathrm{O}_{7}$ and $\mathrm{WO}_{3}$ and to describe their frictional behaviour [29, 30]. It was first recognised by Magnéli et al., that oxides of titanium and vanadium, 


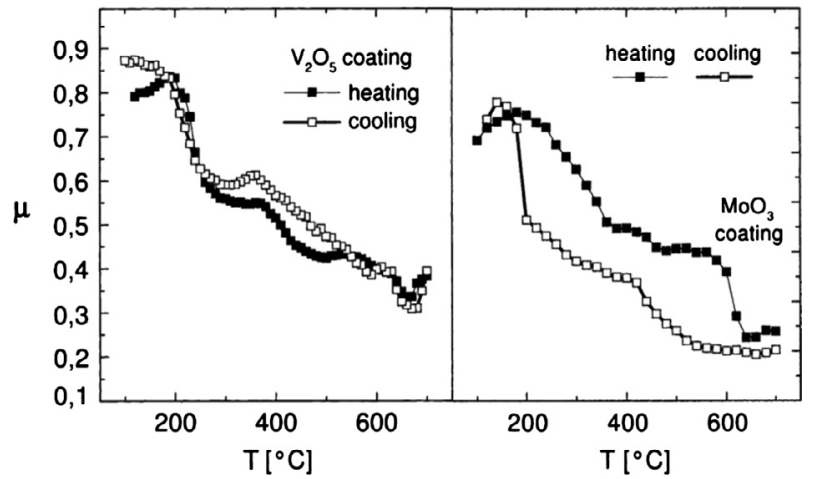

Figure 2. Temperature dependence of $\mathrm{CoF}$ for $\mathrm{V}_{2} \mathrm{O}_{5}$ and $\mathrm{MoO}_{3}$ on alumina substrates. An alumina ball $(\Phi=8 \mathrm{~mm})$ on disc test with a load of $1 \mathrm{~N}$ was used to measure the $\mathrm{CoF}$ with a $10{ }^{\circ} \mathrm{C} / \mathrm{min}$ temperature sweep in the range of $100-700{ }^{\circ} \mathrm{C}$ [30].

as well as those of molybdenum and tungsten, formed homologous series with planar faults of general formulae $(\mathrm{Ti}, \mathrm{V})_{n} \mathrm{O}_{2 n-1}$ [31] or (W, Mo) ${ }_{n} \mathrm{O}_{3 n-1}$ [32]. The oxygen deficient phases of tungsten and vanadium oxides are known to crystallise in the form of Magnéli phases, which offer a wide range of structures generated by the presence of ordered patterns of edge-sharing octahedral within the $\mathrm{ReO}_{3}$ like cornersharing octahedral network. The disordered phase containing crystallographic shear planes with reduced binding strength enables its use as a solid lubricant [33]. In a simplified way, the Magnéli phase structure can be derived from a perfect $\mathrm{V}_{2} \mathrm{O}_{5}$ crystal, which has one missing oxygen layer, i.e. the (1 2 1 $)$ plane, which is called the crystallographic shear (CS) plane and compensates for the non-stoichiometry of the compounds [6]. Due to their oxidation stability and their low tribooxidation sensitivity, some lamellar oxides of these transition metals $\left(\mathrm{WO}_{3}, \mathrm{MoO}_{3}\right.$ and $\left.\mathrm{V}_{2} \mathrm{O}_{5}\right)$ have been considered to be good candidates for low friction coatings [30].

Tungsten and vanadium oxides were deposited by Lugscheider in a reactive DC magnetron sputtering rig and their thermal stability was studied in a high temperature XRD facility [33]. The vanadium oxide phases were stable until $605{ }^{\circ} \mathrm{C}$ and the tungsten oxide phases were stable until $827^{\circ} \mathrm{C}$. A low $\mathrm{CoF}$ of 0.2 was measured on a polished $\mathrm{WO}_{x}$ coated sample sliding against steel at room temperature, while a slightly higher $\mathrm{CoF}(0.2-0.4)$ was measured for the $\mathrm{VO}_{x}$ coated sample [34]. The authors attributed the low CoF to the high hardness of the oxides, but they did not test the tribological behaviour of the coatings at high temperature. Gulbiński et al. found that the $\mathrm{CoF}$ of magnetron sputtering deposited vanadium oxide $\left(\mathrm{V}_{2} \mathrm{O}_{5}\right)$ and molybdenum oxide $\left(\mathrm{MoO}_{3}\right)$ was reduced at high temperature and they followed a similar trend during both heating and cooling (Figure 2) [30].

These oxides or their derivatives can be deposited as coatings on the contact surfaces using reactive PVD techniques, especially magnetron sputtering [8]. However, the poor adhesion resulting from the reactive oxidation process seriously compromises their applications. Another approach is to deposit hard and wear resistant coatings containing VN [18], TiVN [17], MoN and WN [7] which, upon tribo-chemical oxidation

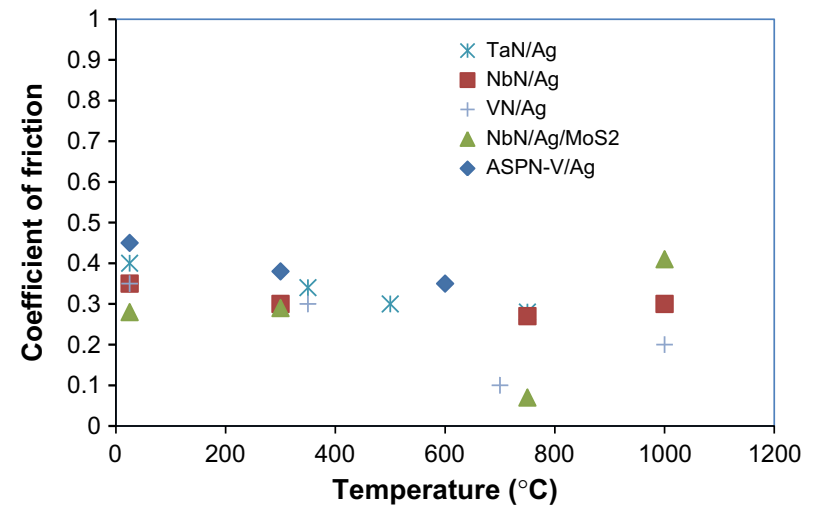

Figure 3. Recorded friction coefficient of $\mathrm{TMeN} / \mathrm{Ag}$ system at different temperatures: $\mathrm{NbN} / \mathrm{Ag}, \mathrm{NbN} / \mathrm{Ag} / \mathrm{MoS}_{2}$ [24], TaN/Ag [25], $\mathrm{VN} / \mathrm{Ag}$ [26] and our research of ASPN-V/Ag.

reactions act as a source of elements for the creation of the desirable lamellar oxides and oxide-derivative phases at elevated temperature. The decrease in friction is a result of the softening or even the micro-melting of appropriate phases generated through tribo-contact, and thus the lubrication effect appears at relatively high temperatures [30].

Tungsten was added to DLC coatings to modify its microstructure via a cathodic arc PVD system. The resulting W-DLC coating offered high wear resistance and low coefficient of friction up to $500{ }^{\circ} \mathrm{C}$ due to the formation of tungsten trioxide $\left(\mathrm{WO}_{3}\right)$ on the surface [35]. However there were some fluctuations in the $\mathrm{CoF}$ at intermedium temperatures $\left(200-300{ }^{\circ} \mathrm{C}\right)$.

\subsection{Nitrides with addition of silver}

$\mathrm{Ag}$ and $\mathrm{Au}$ possess sufficiently low shear strength over a wide temperature range as well as stable thermal chemistry allowing them to be used in both ambient air and vacuum. Monolithic solid lubricants have a limited working range and wear relatively quickly due to their intrinsically soft nature. Silver (Ag) nanoparticles are easily embedded in carbide, oxide and nitride coatings, forming a composite structure. This multiphase structure, consisting of a solid lubricant dispersed in a hard matrix, can be designed so that their surface chemical composition and structure changes to minimise the coefficient of friction and wear rate in a broad range of temperatures. In this way, the soft noble metals with low shear strength and good ductile properties, acts as solid lubricants, and the hard coatings improve the abrasion resistance.

In our research, silver and vanadium were simultaneously deposited on the surface of CM247 superalloy in an active screen plasma nitriding atmosphere (ASPN-V/Ag), and the $\mathrm{CoF}$ of the treated surface against $\mathrm{Al}_{2} \mathrm{O}_{3}$ ball was reduced from 0.45 at room temperature to 0.38 at $300{ }^{\circ} \mathrm{C}$ and 0.35 at $600{ }^{\circ} \mathrm{C}$ (Figure 3). Nitride based nanocomposites consisting of hard (wear resistant) phases and lubricious noble metals have been reported extensively, for example, $\mathrm{Mo}_{2} \mathrm{~N} / \mathrm{Ag}$ [36], $\mathrm{Mo}_{2} \mathrm{~N} / \mathrm{Cu}$ [37], CrN/Ag [38], CrAlN/Ag [39], VN/Ag [38] and $\mathrm{NbN} /$ $\mathrm{Ag}$ [24]. A summary of the CoF of these systems at different temperatures is shown in Figure 3. 


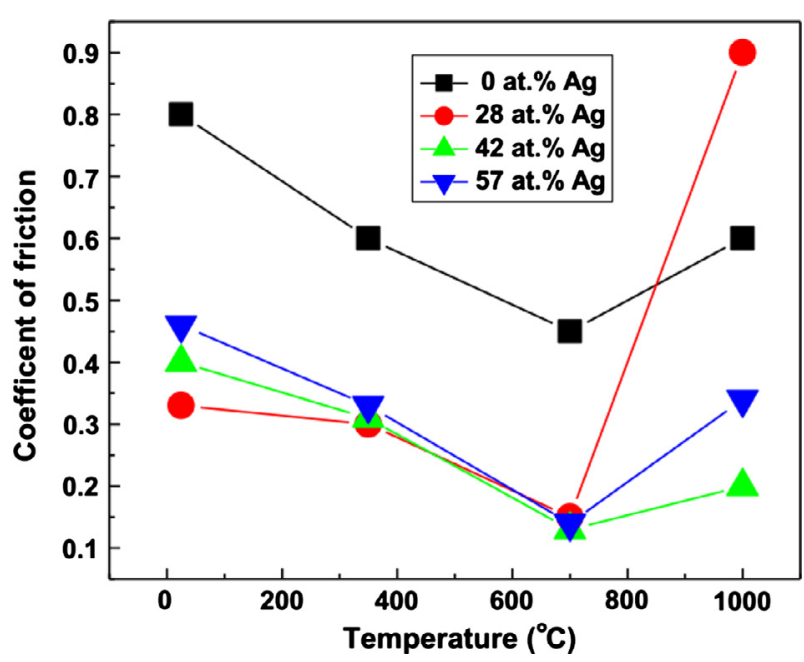

Figure 4. The effect of silver amount in the VN coating on the coefficient of friction for a sliding test performed against $\mathrm{Si}_{3} \mathrm{~N}_{4}$ ball using a $2 \mathrm{~N}$ load [26].

$\mathrm{NbN} / \mathrm{Ag}$ nanocomposite coatings were deposited using unbalanced magnetron sputtering [24]. The inclusion of silver in $\mathrm{NbN}$ significantly reduces the $\mathrm{CoF}$ against $\mathrm{Si}_{3} \mathrm{~N}_{4}$ counterface to below 0.35 in the temperature range between 25 and $1000{ }^{\circ} \mathrm{C}$ (Figure 3). The structural and chemical characterisation after wear testing revealed that, in the low to mid-temperature range, silver migrated to the surface to reduce friction. At higher temperatures, oxygen, silver and the transition metal reacted to form lubricious binary metal oxide phases (silver niobate) in addition to pure silver. Similarly, silver additions can reduce the $\mathrm{CoF}$ of $\mathrm{TaN}$ and $\mathrm{VN}$ significantly, but the amount of silver needs to be carefully controlled and optimised as suggested in Figure 4 [25, 26].

The introduction of silver into $\mathrm{Mo}_{2} \mathrm{~N}$ thin films $\left(\mathrm{Mo}_{2} \mathrm{~N} /\right.$ $\mathrm{Ag}$ ), deposited by magnetron sputtering, had a complex effect. The addition of silver led to a relative low $\mathrm{CoF}$ at high temperature, up to $400{ }^{\circ} \mathrm{C}$. Moreover, the formation of the $\mathrm{MoO}_{3}$ lamellar oxide played a key role in the lubricating mechanism at high temperature. However, the $\mathrm{CoF}$ at room temperature was much higher than that of $\mathrm{Mo}_{2} \mathrm{~N}$ thin film without silver [36]. Copper additions to $\mathrm{Mo}_{2} \mathrm{~N}\left(\mathrm{Mo}_{2} \mathrm{~N} / \mathrm{Cu}\right)$ up to 22 at.\% only had a marginal impact on the tribological behaviour [37].

Mulligan et al. added varying contents of Ag up to 22 at.\% into $\mathrm{CrN}$, via magnetron sputtering deposition. The $\mathrm{CoF}$ against alumina counterface dropped to 0.1 at $500{ }^{\circ} \mathrm{C}$ during ball-on-disc wear tests conducted in the temperature range from 25 to $700{ }^{\circ} \mathrm{C}$. However the $\mathrm{CoF}$ was persistently high $(0.5-0.90)$ in the temperature range from $500{ }^{\circ} \mathrm{C}$ to $700{ }^{\circ} \mathrm{C}$ [38]. The low CoF observed at the beginning of the test was strongly influenced by the size and shape of Ag agglomerates formed during heating on the coating surface, as $\mathrm{Ag}$ is highly mobile in $\mathrm{CrN}$ matrix at elevated temperature (see Figure 5). After the soft phase was worn away, the supply for the Ag from the coating "bulk" either was too low or the Ag reservoir was exhausted due to quick outward diffusion of $\mathrm{Ag}$ [40]. $\mathrm{CrN}$, CrAlN and CrAlN $/ 9$ at. $\%$ Ag coatings were deposited on stainless steel substrates by unbalanced dc magnetron sputtering [39].

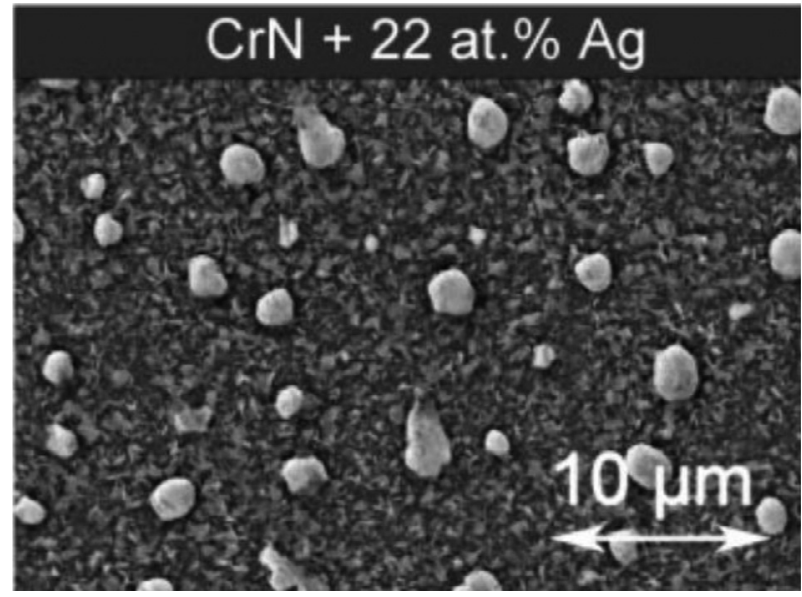

Figure 5. SEM micrographs of the surface of $\mathrm{CrN}-\mathrm{Ag}$ coating indicating formation of $\mathrm{Ag}$ agglomerate of the coatings surface after annealing at $600{ }^{\circ} \mathrm{C}$ for $90 \mathrm{~min}$ [40].

The CoF of these coatings sliding against an alumina ball in air at room temperature were $0.55,0.37$ and 0.23 respectively. The addition of $\mathrm{Ag}$ reduced the coefficient of friction of CrAlN. But it was strongly dependent on the content of Ag.

\subsection{Lubricious oxide with noble metal addition}

Silver (Ag) can also be added to transition metal oxides to form double metal oxides of the type $\mathrm{Me}_{x} \mathrm{TM}_{y} \mathrm{O}_{z}$, where $\mathrm{Me}$ is a lubricious metal like silver and TM is a transition metal. Such oxides were found to exhibit relatively low coefficient of friction (0.1-0.3) in the medium temperature range (500$700{ }^{\circ} \mathrm{C}$ ) [12]. Additionally, silver can form silver molybdate and silver vanadate at higher temperature. Thin films based on the $\mathrm{Ag}_{2} \mathrm{O}-\mathrm{MoO}_{3}, \mathrm{Cu}-\mathrm{V}_{2} \mathrm{O}_{5}$ and $\mathrm{Ag}-\mathrm{V}_{2} \mathrm{O}_{5}$ systems were deposited on alumina substrates via reactive magnetron sputtering by Gulbiński et al. $[8,30]$. As seen in Figure 6 , the coefficient of friction at high temperature was reduced for all the oxides, but it was persistently high at low temperature for most of the coatings. The only exception was $\mathrm{Ag}_{2} \mathrm{MoO}_{4}$ which was chemically stable and the coefficient of friction consistently low in a whole temperature range. $\mathrm{Ag}_{2} \mathrm{MoO}_{4}$ exhibits a layered structure, with alternating $\mathrm{AgO}$ and $\mathrm{MoO}_{3}$ planes separated by a silver layer, with the molybdenum atoms occupying tetrahedral sites and the silver atoms occupying octahedral sites. The weaker Ag-O bridging bonds $(220 \mathrm{~kJ} / \mathrm{mol})$ makes them more prone to shearing and/or breaking at relatively high temperatures than the stronger Mo-O bonds $(560 \mathrm{~kJ} / \mathrm{mol})$ as seen in Figure $7[9,41]$. Stone et al. also found the layered structure of silver molybdate facilitates sliding, resulting in a low $\mathrm{CoF}$ $(<0.2)$ from $300{ }^{\circ} \mathrm{C}$ to $500{ }^{\circ} \mathrm{C}[9]$. Silver and copper vanadates $\left(\mathrm{AgV}_{x} \mathrm{O}_{y}\right.$ and $\left.\mathrm{CuMo}_{x} \mathrm{O}_{y}\right)$ demonstrated a low $\mathrm{CoF}$ of 0.2 at temperature around $500{ }^{\circ} \mathrm{C}[30]$.

\subsection{Other blending}

It is clear that the $\mathrm{CoF}$ can be reduced at medium and high temperatures by doping nanocomposite coatings with silver. 


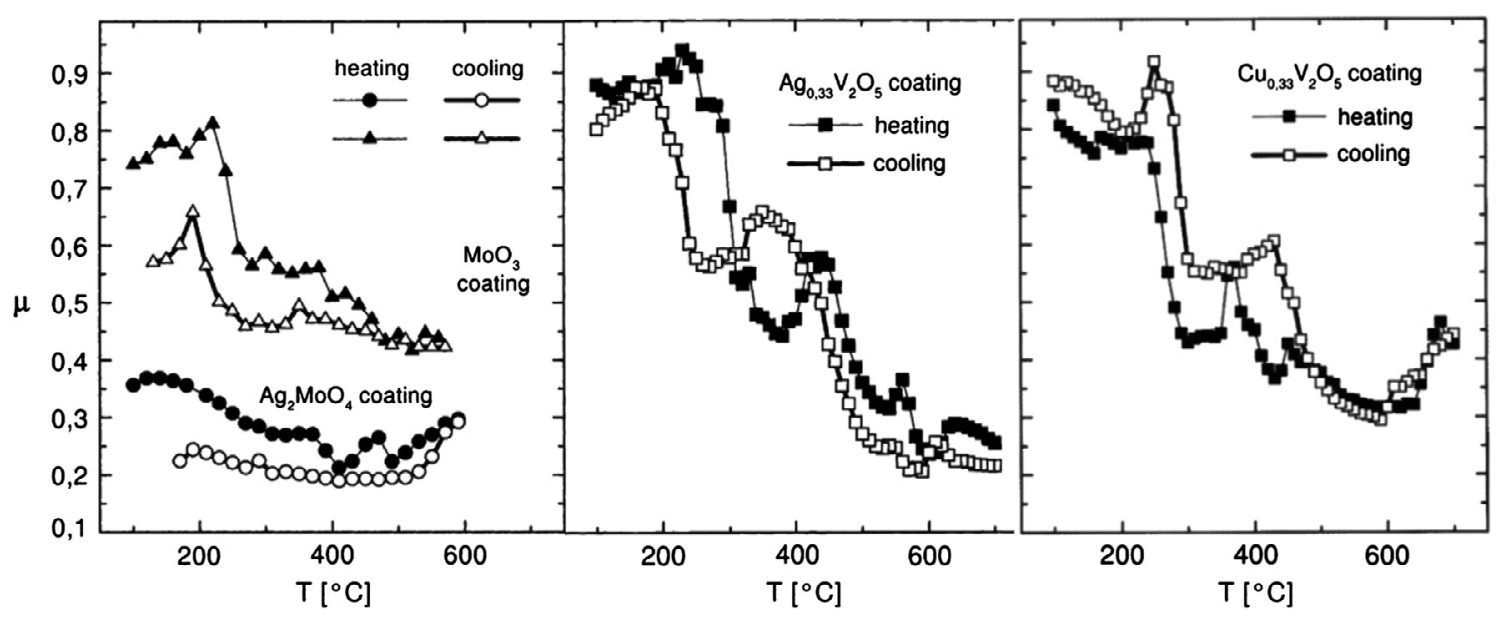

Figure 6. Temperature dependence of $\mathrm{CoF}$ for $\mathrm{MoO}_{3}, \mathrm{Ag}_{2} \mathrm{MoO}_{4}, \mathrm{Ag}_{0.33} \mathrm{~V}_{2} \mathrm{O}_{5}$ and $\mathrm{Cu}_{x} \mathrm{~V}_{2} \mathrm{O}_{5}$ coatings on alumina substrates. An alumina ball $(\Phi=8 \mathrm{~mm})$ on disc test with a load of $1 \mathrm{~N}$ was used to measure the $\mathrm{CoF}$ with a $10^{\circ} \mathrm{C} / \mathrm{min}$ temperature sweep in the range of $100-700{ }^{\circ} \mathrm{C}[30]$.

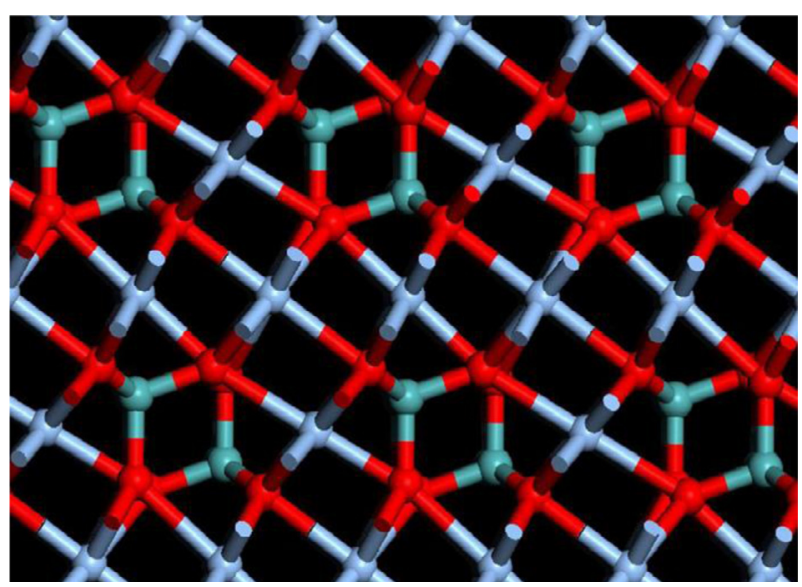

Figure 7. Diagram depicting the structure for $\mathrm{Ag}_{2} \mathrm{MoO}_{4}$. The blue, green, and red spheres represent $\mathrm{Ag}, \mathrm{Mo}$, and $\mathrm{O}$, respectively [41].

However, the CoF is persistantly high at low temperature due to the lack of solid lubricants acting in this tempearature range. Therefore, additional lubricious phases, such as graphite/DLC or $\mathrm{MoS}_{2}$, have been introduced in the nanocomposite to generate dual-phase lubricating materials which provide adaptive lubrication over an extended temperature range. An Ag$\mathrm{MoS}_{2}$ nanoparticle-based multi-component lubricating system was developed to improve the durability and to enhance the tribological and thermal properties of $\mathrm{MoS}_{2}$ [42]. The silver and $\mathrm{MoS}_{2}$ in the coating provided adequate lubrication at lowtemperature. A silver molybdate phase formed at moderate temperature $\left(350-600{ }^{\circ} \mathrm{C}\right.$ ) and it decomposed into $\mathrm{MoO}_{3}$ at higher temperature, providing lubrication between $600{ }^{\circ} \mathrm{C}$ and $700{ }^{\circ} \mathrm{C}$. In a separate study, nano-composite films consisting of tungsten disulfide $\left(\mathrm{WS}_{2}\right)$ with $50 \mathrm{wt} . \%$ zinc oxide $(\mathrm{ZnO})$ were powder burnished on Inconel substrates [43]. The nanocrystalline $\mathrm{ZnO}$ additive resulted in a significant reduction in the $\mathrm{CoF}$ of $\mathrm{WS}_{2}$ against stainless steel counterface up to $500{ }^{\circ} \mathrm{C}$ from 0.50 to 0.22 , due to the formation of zinc tungstate $\left(\mathrm{ZnWO}_{4}\right)$. Other solid lubricant composites based on oxides and dichalcogenides $\left(\mathrm{PbO} / \mathrm{MoS}_{2}, \mathrm{ZnO} / \mathrm{MoS}_{2}\right)$ which could operate in a broad temperature range, were also explored in earlier research $[44,45]$. In the case of molybdenum disulfide $\left(\mathrm{MoS}_{2}\right)$ and lead oxide $(\mathrm{PbO})$ adaptive lubricating system, $\mathrm{MoS}_{2}$ provides lubrication at ambient and intermediate temperatures, and a lead molybdate compound $\left(\mathrm{PbMoO}_{4}\right)$ is formed as the temperature increases, providing continuous lubrication [45].

The addition of $\mathrm{MoS}_{2}$ to the $\mathrm{NbN} / \mathrm{Ag}$ coating system, further reduced the coefficient of friction of the coating up to $750{ }^{\circ} \mathrm{C}$, as seen in Figure $3[24,41]$.

\section{Multi-layerd structure and duplex system}

\subsection{Multi-layered structure}

The use of a large number of alternating thin layers, such as $\mathrm{TiN} / \mathrm{NbN}$, forming a multilayer/superlattice coating can reduce the propagation of cracks, and yield finer grain sizes, leading to higher hardness and improved tribological properties [46]. The modern trend is to use multilayer coatings tailored to combat different types of wear and provide a synergistic tribological effect. In a typical $\mathrm{TiC} / \mathrm{Al}_{2} \mathrm{O}_{3} / \mathrm{TiN}$ multilayer coating produced by $\mathrm{CVD}$, TiC resists abrasive flank wear, $\mathrm{Al}_{2} \mathrm{O}_{3}$ provides good chemical protection for the rake face, and TiN provides lower friction as well higher hardness [47].

Three nanostructured coatings, namely VAIN, VAIN/ VCAIN and VAIN/VCAIN with a carbon-enriched top layer were deposited by high-frequency magnetron sputtering to improve the life time of forming tools [22]. All coatings showed a stable frictional behaviour $(\mathrm{CoF}<0.1)$ within the examined range of surface pressure up to $150 \mathrm{MPa}$. However the coatings' response to temperature was not discussed.

Multilayered coatings consisting of ceramic-metal nanocomposite adaptive lubricating layers separated by diffusion barriers allowed adaptation to occur only upon exposure of the lubricant layer by wear, which resulted in prolonged wear life at static and cycled temperatures. The number and the 
thickness of the individual layer are important because diffusion and oxidation-based adaptation in these particular coatings required a minimum volume of solid lubricant material and hard wear resistance materials [48]. By carefully designing the multilayer system, $\mathrm{CoF}$ (against silicon nitride counterface) below 0.2 can be sustained over multiple thermal cycles from room temperature to $700{ }^{\circ} \mathrm{C}$.

A multilayer system based on $\mathrm{Mo}_{2} \mathrm{~N} / \mathrm{MoS}_{2} / \mathrm{Ag}$ was deposited on Inconel via unbalanced magnetron sputtering with individual targets of $\mathrm{Mo}, \mathrm{MoS}_{2}$ and $\mathrm{Ag}$ [41]. The objective was to improve the tribological properties of these materials in the temperature range from $0{ }^{\circ} \mathrm{C}$ to $700{ }^{\circ} \mathrm{C}$, by three different adaptive mechanisms. From $0{ }^{\circ} \mathrm{C}$ to $300{ }^{\circ} \mathrm{C}$, the lubrication was provided by $\mathrm{MoS}_{2}$ because of its lamellar structure. From $300{ }^{\circ} \mathrm{C}$ to $500{ }^{\circ} \mathrm{C}$, the lubrication was provided by the migration of the noble metal to the surface. In this temperature range, the migration of silver to the surface would be dramatically reduced by its strong affinity to sulphur. From $500{ }^{\circ} \mathrm{C}$ to $700{ }^{\circ} \mathrm{C}$, the sulphur in $\mathrm{MoS}_{2}$ acted as a catalyst for the formation of lubricious compounds as the result of the reaction with silver $\left(\mathrm{MoS}_{x}+\mathrm{Ag} \rightarrow \mathrm{AgMoS}_{x}\right)$, with the sulphur atoms being replaced by oxygen atoms at temperatures above $500{ }^{\circ} \mathrm{C}$. The system performed well at $600{ }^{\circ} \mathrm{C}$, maintaining a low $\mathrm{CoF}$ against silicon nitride counterface of 0.1 for 300,000 cycles due to the formation of three types of silver molybdate phases, namely, $\mathrm{Ag}_{2} \mathrm{Mo}_{4} \mathrm{O}_{13}, \mathrm{Ag}_{2} \mathrm{Mo}_{2} \mathrm{O}_{7}$ and $\mathrm{Ag}_{2} \mathrm{MoO}_{4}$. The layered structure of $\mathrm{Ag}_{2} \mathrm{MoO}_{4}$ was discussed earlier. The $\mathrm{Ag}_{2} \mathrm{Mo}_{2} \mathrm{O}_{7}$ structure consisted of $\left[\mathrm{Mo}_{4} \mathrm{O}_{16}\right]_{8^{-}}$chains linked through $\mathrm{O}-\mathrm{Ag}-\mathrm{O}$ bridging bonds to form a $3 \mathrm{D}$ network, that made them more prone to shearing and/or breaking at relatively high temperatures [41]. However, the reduction of $\mathrm{CoF}$ at RT (0.6-0.4) and at $350{ }^{\circ} \mathrm{C}(0.3)$ was not pronounced.

In the $\mathrm{YSZ} / \mathrm{Au} / \mathrm{MoS}_{2} / \mathrm{DLC}$ system [49] produced by a combination of laser ablation and magnetron sputtering, load bearing was provided by the yittria stabilised zirconia (YSZ) and the DLC phases, while the lubrication was provided by the other three phases: (1) Au for temperatures above $300{ }^{\circ} \mathrm{C}$ (CoF 0.10-0.20), (2) hexagonal $\mathrm{MoS}_{2}$ for temperatures below $300{ }^{\circ} \mathrm{C}$ in vacuum or in dry environments (CoF $0.02-$ 0.05 ) and, (3) graphite, formed as a by-product of the DLC phase during sliding contact, for temperatures below $300{ }^{\circ} \mathrm{C}$ in humid environments ( $\mathrm{CoF} 0.10-0.15)$.

Other multilayer nanocomposites including WC/DLC/ $\mathrm{WS}_{2}$, and $\mathrm{Al}_{2} \mathrm{O}_{3} / \mathrm{Au} / \mathrm{MoS}_{2} / \mathrm{DLC}$ have also been discussed [24]. The $\mathrm{WC} / \mathrm{DLC} / \mathrm{WS}_{2}$ composites exhibited excellent friction recovery in humid and dry environmental cycling. Their CoFs were about 0.1 in humid air, 0.03 in vacuum, and as low as 0.007 in dry nitrogen [50].

A ternary boron based Ti-B-N gradient coating in specific multilayer designs, which minimise the high internal stress of $\mathrm{TiB}_{2}$, obtained through plasma enhanced chemical vapour deposition (PECVD) was applied onto hot forming tools made from DIN 1.2367 tool steel [51]. After 3000 cycles stamping of AISI 1043 raw parts at $1150^{\circ} \mathrm{C}$, the coating with special designed 25 graded $\operatorname{Ti}(\mathrm{N} \rightarrow \mathrm{B}) / \mathrm{Ti}(\mathrm{B} \rightarrow \mathrm{N})$ layers greatly reduced tool's adhesion and abrasive wear in comparison with that of untreated and plasma nitrided tools.

\subsection{Duplex system: the application of textured surface and Nanotube}

Duplex system, which combines two or more established surface engineering techniques together, has been used to fight against challenging working condition [52]. High speed steel (HS6-5-2c) material was pre-treated with plasma nitriding first, and then deposited with a hard and lubricious TiAlVN coating via magnetron sputtering [21]. The friction coefficient at $500{ }^{\circ} \mathrm{C}$ was lower than that of the room temperature which was due to the forming of lubricious oxide.

The combination of solid lubricants with nanocomposites has provided a versatile option to extend the working temperature range. However, due to the consumption and diffusion of solid lubricants at elevated temperature, it is difficult to preserve their effect for extended operation. Therefore, many attempts have been reported to modify the coating structure using textured surfaces and nanotubes as reservoirs for lubricants. Many different techniques have been used to introduce surface textures and create favourable architectures, which can accommodate the solid lubricants, such as: laser texturing [53], lithography [54, 55], reactive ion etching [56, 57], pulsed air arc treatment [58] and sprayed ceramic beads [59]. All these techniques are used to produce well-defined circular or rectangular depressions or dimples on the surface of hard coatings (either single or multiphase). The size of these defects/pores can be controlled and their distribution should be uniformly spread on the surface, as they will serve as lubricant reservoirs over the tribological contact. Solid lubricant coatings can then be applied by PVD, especially by sputter deposition and evaporation, pulsed laser ablation, burnishing/ impingement or metal organic chemical vapour deposition (MOCVD) [3, 4]. The lubricant layer can then be replenished, thus minimising the amount of deformation during the sliding process and increasing the lifetime of the contacting surfaces.

In Voevodin and Zabinski's research [53], powerful lasers with short wavelengths and pulse durations were used to create 10-20 $\mu \mathrm{m}$ reservoirs on TiCN coatings, causing minimum damage to the areas surrounding the reservoirs. A multifold increase in the wear life of burnished and sputtered $\mathrm{MoS}_{2}$ on textured TiCN coatings was demonstrated in comparison with that of monolithic TiCN films. The introduction of $\mathrm{MoS}_{2} /$ graphite/ $\mathrm{Sb}_{2} \mathrm{O}_{3}$ in the pores helped to keep a layer of solid lubricant on the surface, which worked reliably under cyclic humid and dry conditions. Different dimple diameters and spacing were used to cover an area with micro-reservoirs between $0.5 \%$ and $50 \%$ of the entire tribological contact surface and the best tribological effect was attained with an optimum dimple surface coverage of about $10 \%$. Basnyat et al. used reactive ion etching to fabricate $80 \mu \mathrm{m}$ sized dimple patterns on TiAlCN films produced by cathodic arc vacuum evaporation [56]. Single-phase $\mathrm{MoS}_{2}$ and multi-phase $\mathrm{MoS}_{x}-\mathrm{Ag}$ solid lubricants were subsequently deposited on the microtextured TiAlCN film, via unbalanced magnetron sputtering. At $570{ }^{\circ} \mathrm{C}$, the addition of $\mathrm{Ag}$, Mo and $\mathrm{MoS}_{2}$ was found to significantly decrease the CoFs as a result of the migration of $\mathrm{Ag}$ to the surface and the formation of lubricious silver molybdate 

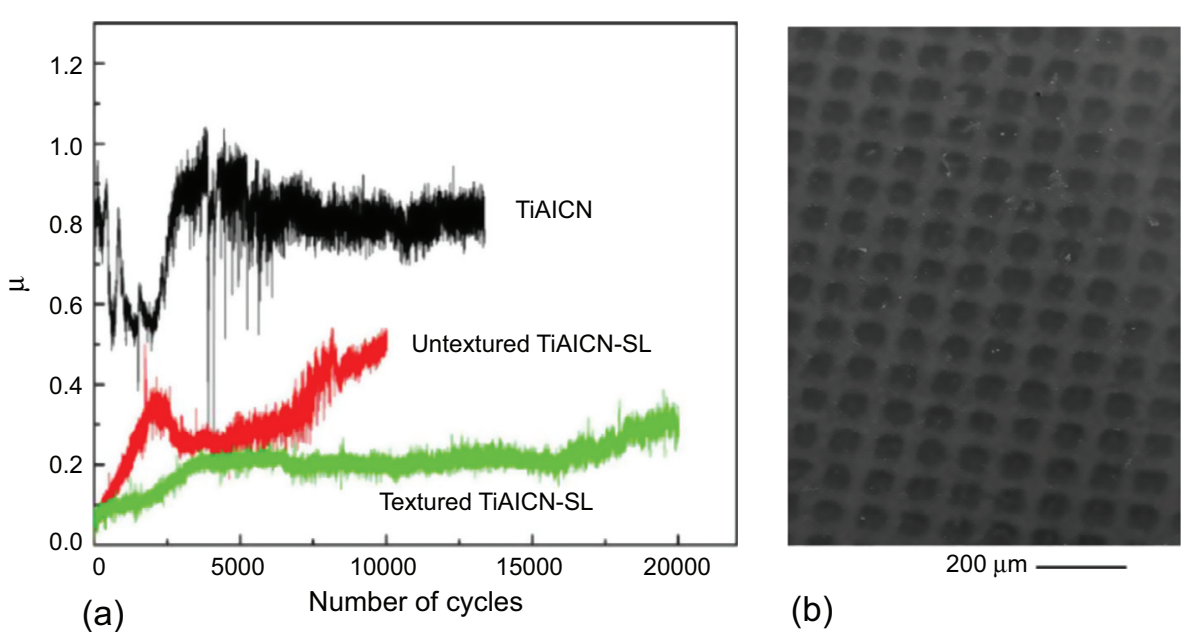

(b)

Figure 8. (a) $\mathrm{CoF}$ for TiAlCN, textured and untextured $\mathrm{TiAlCN}+\mathrm{Mo} / \mathrm{MoS} \mathrm{S}_{2} / \mathrm{Ag}$ coatings recorded at $570{ }^{\circ} \mathrm{C}$ against $\mathrm{Si}_{3} \mathrm{~N}_{4}$ ball with a load of $1 \mathrm{~N}$ in dry air. (b) SEM micrograph for textured TiAlCN coating [56].

phases. The presence of pores containing solid lubricant materials reduced the coefficient of friction and improved the longevity of the coating by a factor of 2, as seen in Figure 8.

Reactive ion etching (RIE) was also used to create arrays of micro-scale dimples on sputtered VN coatings on Inconel alloy substrates, and the pores were subsequently filled with $\mathrm{Ag}_{3} \mathrm{VO}_{4}$ powders by burnishing [57]. It was found that the textured films with burnished powders had a low $\mathrm{CoF}$ (against $\mathrm{Si}_{3} \mathrm{~N}_{4}$ counterface) of 0.2 at $750{ }^{\circ} \mathrm{C}$, and were more effective in enhancing the tribological properties when compared to burnished/un-burnished monolithic VN coatings.

Moskovitch et al. applied the pulsed air arc treatment to produce dimples on the surface of stainless steel specimens and $\mathrm{MoS}_{2}$ was then burnished with stearin on the textured surface, which significantly extended its lifetime [58]. Zimmerman et al., utilised ceramic beads $(1.5-10 \mu \mathrm{m}$ diameter) as placeholders during the deposition of a TiN coating by reactive sputter deposition. The beads were removed by sonication, creating micro-pores which were finally filled with a solid lubricant, like graphite [59]. The authors claimed a substantial improvement on the tribological properties of TiN with a textured surface formed by using $10 \mu \mathrm{m}$ beads. Krzanowski et al. used photolithography, a well-established method for patterning semiconductors, to create a regular array of micron-size islands on the surface of the substrate. Various coatings were applied on the substrate, including $\mathrm{Cr}, \mathrm{TiC}$ and $\mathrm{MoS}_{2}$, via sputter deposition, to create a three-dimensional structure in a tribological composite coating [55].

Carbon nanotubes (CNT) with superior strength, thermal, and electrical properties provided the chance to create a versatile tuneable, multifunctional tribological system [60]. The CoFs of carbon nanotubes varied widely from less than 0.1-1.0. A high CoF was obtained for vertically aligned CNTs while a very low value was obtained for the CNTs dispersed flat on substrates. Self-lubricating CNT composites were created by electrodepositing molybdenum disulfide $\left(\mathrm{MoS}_{2}\right)$ on vertically aligned multi-walled carbon nanotubes (MWNTs) [61]. These composite films displayed much better

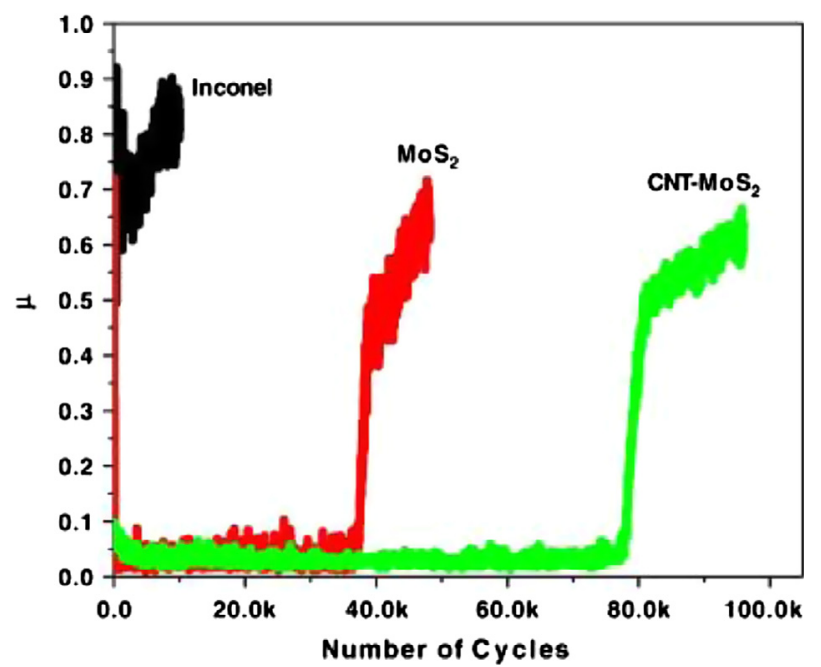

Figure 9. CoF measured in dry air using a $1 \mathrm{~mm}$ diameter alumina ball under $1 \mathrm{~N}$ load on bare Inconel disc, electrodeposited $\mathrm{MoS}_{2}$, and CNT-MoS $\mathrm{C}_{2}$ composite film plotted as a function of number of wear cycles $[12,61]$.

performance than the monolithic $\mathrm{MoS}_{2}$ coatings under the same operating conditions without compromising $\mathrm{CoF}$ values $(0.04)$ as seen in Figure 9. The film exhibit low $\mathrm{CoF}(\sim 0.03)$ and wear rate $\left(\sim 10^{-13} \mathrm{~mm}^{3} / \mathrm{N} \mathrm{mm}\right)$ even at $300{ }^{\circ} \mathrm{C}$, which were about twofold better than those of nanoparticulate $\mathrm{MoS}_{2}$-based coatings. The CNTs, with high load-bearing capacity, provided a strong enduring support for the $\mathrm{MoS}_{2}$ nanoclusters and were responsible for their ultralow wear. The MWNT/MoS ${ }_{2}$ coating displayed a low CoF both in humid $(\sim 0.16)$ as well as in dry $(\sim 0.05)$ air and was able to sustain its frictional properties under cyclic non-humid/humid environments. Similarly, the tribological properties of CNT/Ag composites were improved in comparison to their constituent materials both at $25^{\circ} \mathrm{C}$ and at $500{ }^{\circ} \mathrm{C}$ [62]. The improved performance of the self-lubricating CNT composites could be due 


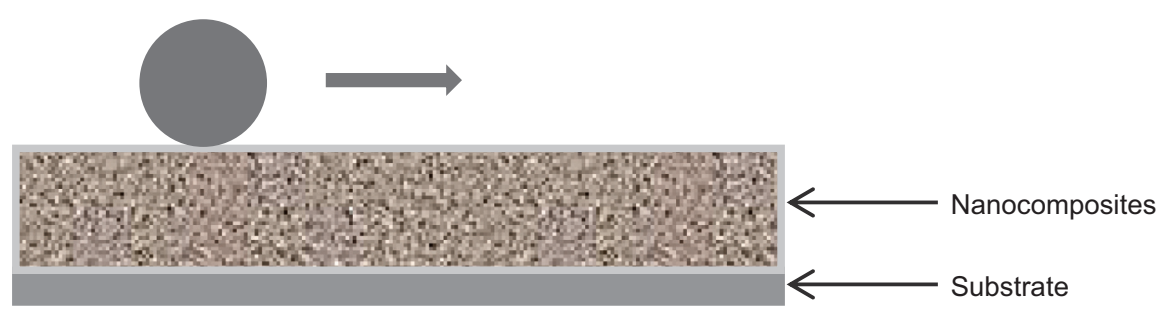

(a)

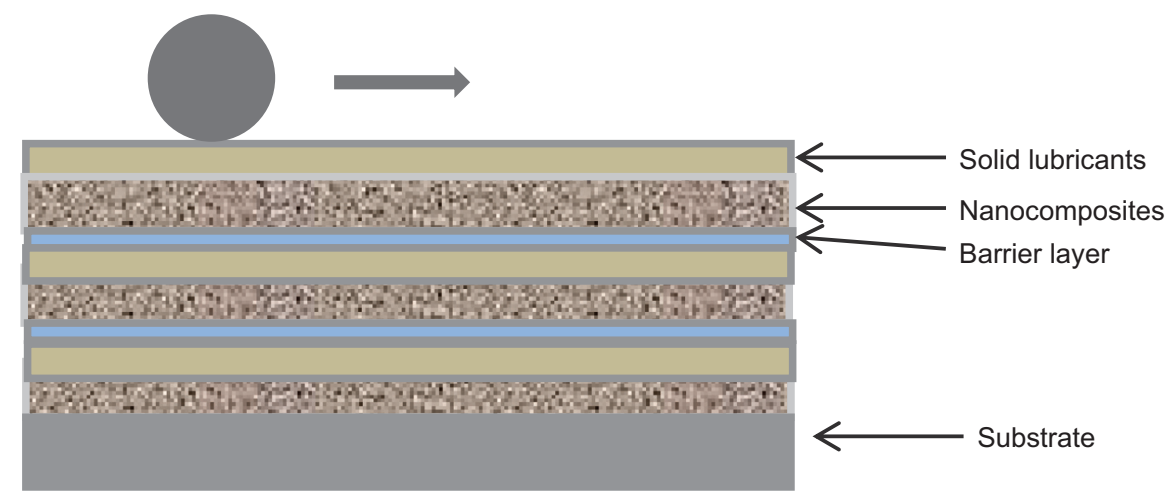

(b)

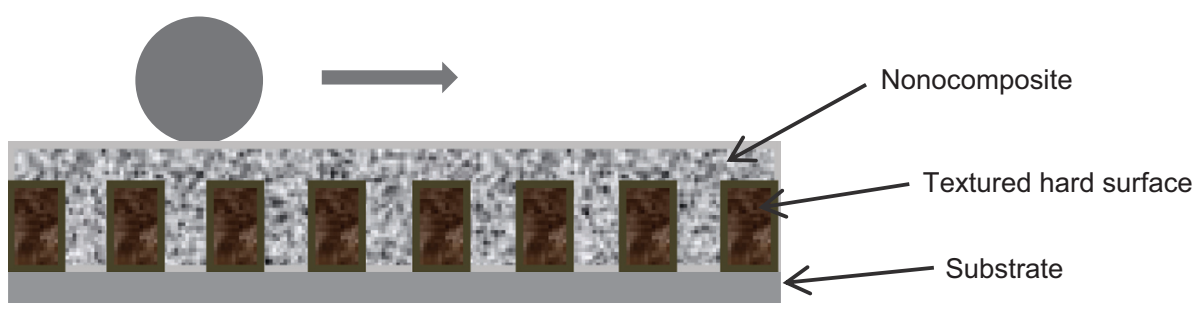

(c)

Figure 10. Schematic diagrams of three classes of adaptive coatings: (a) nanocomposites; (b) multi-layer structured coatings; (c) nanocomposite coatings on textured hard coatings.

to (1) the high strength and fracture toughness provided by the nanotubes; (2) the self-lubricating nature of the CNTs as they turn into graphite when worn; (3) the lateral-support provided by the solid lubricants i.e. $\mathrm{MoS}_{2}$ or $\mathrm{Ag}$ to the CNTs preventing them from breaking under relatively high loads [61].

Boron nitride nanotubes (BNNTs) have a similar structure to CNTs and they have low $\mathrm{CoF}$ and good thermal stability. Under a compression load, the bending angles of BNNTs can be extended beyond $30-40^{\circ}$ resulted in the elastic deformation, which proceed through the propagation of consecutive momentary kinks, therefore they have the effect of accumulating a bending curvature rather than uniformly curling as CNTs behave. BNNTs were also used to incorporate solid lubricants to form a Nanotube/self-lubricating coatings for tribological applications [63].

\section{Summary and concluding remarks}

\subsection{Summary and conclusions}

The last decades have seen progress in applying existing solid lubricants and hard and wear resistant materials on different tool surfaces to meet an increasing demand for high-performance and long-life forming tools in hightemperature environments.

Monolithic nitrides such as $\mathrm{CrN}$ and $\mathrm{TiN}$ have been extensively investigated by adding such alloying elements as $\mathrm{Al}, \mathrm{Si}$ and $\mathrm{V}$ to mainly enhance their high temperature wear resistance and to some extent to reduce their coefficient of friction $(\mathrm{CoF})$. In order to further reduce $\mathrm{CoF}$, other refractory metal nitrides $\mathrm{VN}, \mathrm{WN}, \mathrm{MoN} / \mathrm{Mo}_{2} \mathrm{~N}, \mathrm{NbN}$ and $\mathrm{TaN}$ have been studied due to the possibility of forming Magnéli phase at high temperature, and among them, VN seems most promising. In the meantime, Magnéli oxides including $\mathrm{V}_{2} \mathrm{O}_{5}, \mathrm{MO}_{3}$ and $\mathrm{WO}_{3}$ have also been explored for their friction and wear properties, but they can only perform well at temperatures ranging from 500 to $700{ }^{\circ} \mathrm{C}$. Therefore noble metals such as silver were added into the oxides and nitrides to form composites thus providing extra solid lubrication at temperatures below $500{ }^{\circ} \mathrm{C}$ and it is also beneficial for lubrication up to $100{ }^{\circ} \mathrm{C}$; other solid lubricants like $\mathrm{MoS}_{2}$, carbon-based materials were also introduced into the composite coatings to reinforce its adaptability. The composite coatings either with monolithic nanocomposite or incorporated with multi-elements or blended with other lubricants or composites have a layer structure as shown in Figure 10a. 
Multi-layer structured coating is another option to increase the adaptability and longevity of coatings for demanding environment. Figure $10 \mathrm{~b}$ is one of the typical designs of multilayer system consisting of alternating solid lubricant layer and hard nanocomposite/barrier layer, which could confer the system with low-friction and high wear resistance.

More recent development is to increase the bonding or retention of coatings by texturing the hard coating surfaces (such as TiAlN) before applying lubricant containing nanocomposite coating (Figure 10c).

Selection of proper coating or surface treatment plays an important role in the process of obtaining the best performance of forming tools. This selection depends greatly on the type of material to be formed. For very soft metals (aluminium and aluminium alloys) with a high degree of plastic deformation during forming, nitrided forming tool steels and nitride-type coatings show a good resistance against galling and a relatively stable friction. For materials that show a high tendency to galling and transfer layer reception (titanium and titanium alloys), only plasma nitriding and $\mathrm{VN}$ coatings give some improvement in galling performance [64].

\subsection{Challenges and future directions}

Notwithstanding the fact that a variety of coating systems with different constituent phases and structures have been researched to reduce coefficient of friction and enhance wear resistance under high-temperature environment, there are still some major challenges in designing advanced adaptive coatings:

1. how to apply the coating systems to improve their adhesion on substrate and the cohesion of different layers;

2. how to control the self-lubrication process;

3. how to achieve low $\mathrm{CoF}$ and wear in different temperatures;

4. how to maintain the excellent mechanical properties of the hard case; and

5. how to maximise the benefit of different constituents in the coatings.

Currently, there is no universal coating that can be effective in a wide range of temperatures. Therefore, future research development should be focused on the following areas:

1. To conduct research into material transfer, adhesion, friction and wear at different temperatures for different tribo-pairs, thus advancing scientific understanding and providing data for surface and coating design.

2. To design new surface and coating systems using novel nanocomposite materials with low friction and high wear resistance in a wide range of temperatures.

3. To develop smart surfaces and coating systems with selfhealing, self-lubrication and anti-galling capabilities for high-temperature forming of ductile and reactive materials (such as $\mathrm{Al}$ and Ti alloys).
Acknowledgements. The authors would like to express their appreciation to the European Commission for the support of the projects Micro-FAST (GA608720) and LoCoLite (GA604240). In addition, the critical reading of the manuscript and constructive suggestions regarding it by our colleague Dr. Santiago Corujeira Gallo is also acknowledged.

\section{References}

1. H. Paschke, M. Weber, G. Braeuer, T. Yilkiran, B.A. Behrens, H. Brand, Optimized plasma nitriding processes for efficient wear reduction of forging dies, Archives of Civil and Mechanical Engineering 12 (2012) 407-412.

2. A. Shokrani, V. Dhokia, S.T. Newman, Environmentally conscious machining of difficult-to-machine materials with regard to cutting fluids, International Journal of Machine Tools and Manufacture 57 (2012) 83-101.

3. T.W. Scharf, S.V. Prasad, Solid lubricants: a review, Journal of Materials Science 48 (2013) 511-531.

4. T.W. Scharf, S.V. Prasad, M.T. Dugger, P.G. Kotula, R.S. Goeke, R.K. Grubbs, Growth, structure, and tribological behavior of atomic layer-deposited tungsten disulphide solid lubricant coatings with applications to MEMS, Acta Materialia 54 (2006) 4731-4743.

5. H.E. Sliney. Self-lubricating fluoride-metal composite materials. USA: US3419363A; 1968.

6. B. Stegemann, M. Klemm, S. Horn, M. Woydt, Switching adhesion forces by crossing the metal-insulator transition in Magnéli-type vanadium oxide crystals, Beilstein Journal of Nanotechnology 2 (2011) 59-65.

7. G. Gassner, P.H. Mayrhofer, K. Kutschej, C. Mitterer, M. Kathrein, Magnéli phase formation of PVD Mo-N and W-N coatings, Surface \& Coatings Technology 201 (2006) 3335-3341.

8. W. Gulbiński, T. Suszko, Thin films of $\mathrm{MoO}_{3}-\mathrm{Ag}_{2} \mathrm{O}$ binary oxides - the high temperature lubricants, Wear 261 (2006) 867-873.

9. D. Stone, et al., Layered atomic structures of double oxides for low shear strength at high temperatures, Scripta Materialia 62 (2010) 735-738.

10. C. Higdon, et al., Friction and wear mechanisms in $\mathrm{AlMgB}_{14}{ }^{-}$ $\mathrm{TiB}_{2}$ nanocoatings, Wear 271 (2011) 2111-2115.

11. R. Cherukuri, M. Womack, P. Molian, A. Russell, Y. Tian, Pulsed laser deposition of $\mathrm{AlMgB}_{14}$ on carbide inserts for metal cutting, Surface and Coatings Technology 155 (2002) 112-120.

12. S.M. Aouadi, B. Luster, P. Kohli, C. Muratore, A.A. Voevodin, Progress in the development of adaptive nitride-based coatings for high temperature tribological applications, Surface and Coatings Technology 204 (2009) 962-968.

13. K.-D. Bouzakis, N. Michailidis, G. Skordaris, E. Bouzakis, D. Biermann, R. M'Saoubi, Cutting with coated tools: Coating technologies, characterization methods and performance optimization, CIRP Annals - Manufacturing Technology 61 (2012) 703-723.

14. K. Kutschej, C. Mitterer, C. Mulligan, D. Gall, High-temperature tribological behavior of $\mathrm{CrN}-\mathrm{Ag}$ self-lubricating coatings, Advanced Engineering Materials 8 (2006) 1125-1129.

15. K. Kutschej, N. Fateh, P.H. Mayrhofer, M. Kathrein, P. Polcik, C. Mitterer, Comparative study of $\mathrm{Ti}_{1-\mathrm{x}} \mathrm{Al}_{\mathrm{x}} \mathrm{N}$ coatings alloyed with Hf, Nb, and B, Surface and Coatings Technology 200 (2005) 113-117. 
16. V. Braic, A. Vladescu, M. Balaceanu, C.R. Luculescu, M. Braic, Nanostructured multi-element (TiZrNbHfTa)N and (TiZrNbHfTa)C hard coatings, Surface and Coatings Technology 211 (2012) 117-121.

17. J.H. Ouyang, T. Murakami, S. Sasaki, High-temperature tribological properties of a cathodic arc ion-plated $(\mathrm{V}, \mathrm{Ti}) \mathrm{N}$ coating, Wear 263 (2007) 1347-1353.

18. N. Fateh, G.A. Fontalvo, G. Gassner, C. Mitterer, The beneficial effect of high-temperature oxidation on the tribological behaviour of V and VN coatings, Tribology Letters 28 (2007) 1-7.

19. K. Kutschej, P.H. Mayrhofer, M. Kathrein, P. Polcik, C. Mitterer, Influence of oxide phase formation on the tribological behaviour of Ti-Al-V-N coatings, Surface and Coatings Technology 200 (2005) 1731-1737.

20. P.H. Mayrhofer, P.E. Hovsepian, C. Mitterer, W.D. Münz, Calorimetric evidence for frictional self-adaptation of TiAlN/ VN superlattice coatings, Surface and Coatings Technology 177-178 (2004) 341-347.

21. W. Tillmann, S. Momeni, F. Hoffmann, A study of mechanical and tribological properties of self-lubricating TiAlVN coatings at elevated temperatures, Tribology International 66 (2013) 324-329.

22. D. Becker, Wear of nanostructured composite tool coatings, Wear 304 (2013) 88-95.

23. K. Bobzin, N. Bagcivan, M. Ewering, R.H. Brugnara, Vanadium alloyed PVD CrAIN coatings for friction reduction in metal forming applications, Tribology in Industry 34 (2012) 101-107.

24. D.S. Stone, et al., Adaptive NbN/Ag coatings for high temperature tribological applications, Surface and Coatings Technology 206 (2012) 4316-4321.

25. D.S. Stone, et al., Lubricious silver tantalate films for extreme temperature applications, Surface and Coatings Technology 217 (2013) 140-146.

26. S.M. Aouadi, et al., Adaptive VN/Ag nanocomposite coatings with lubricious behavior from 25 to $1000{ }^{\circ} \mathrm{C}$, Acta Materialia 58 (2010) 5326-5331.

27. C. Bruce, G. Kerry, Tough nanocoatings boost industrial energy efficiency, Ames Laboratory, US Department of Energy, 2008.

28. A.H. Shaw, Wear-resistance, lubricity, and adhesion of femtosecond pulsed laser deposited $\mathrm{AlMgB}_{14}$-based thin films [MASTER OF SCIENCE]: 2011. Iowa State University.

29. M.N. Gardos, The problem-solving role of basic science in solid lubrication. In I.M. Hutchings, editor. the First World Tribology Congress. Mechanical Engineering Publications, London, 1997, pp. 229-250.

30. W. Gulbiński, T. Suszko, W. Sienicki, B. Warcholiński, Tribological properties of silver- and copper-doped transition metal oxide coatings, Wear 254 (2003) 129-135.

31. S. Andersson, A. Magnéli, Diskrete Titanoxydphasen im Zusammensetzungsbereich TiO1,75-TiO1,90, Natur wissenschaften 43 (1956) 495-496.

32. A. Magnéli, Structures of the $\mathrm{ReO}_{3}$-type with recurrent dislocations of atoms: "homologous series" of molybdenum and tungsten oxides, Acta Crystallographica 6 (1953) 495-500.

33. E. Lugscheider, S. Bärwulf, C. Barimani, Properties of tungsten and vanadium oxides deposited by MSIP-PVD process for selflubricating applications, Surface and Coatings Technology 120-121 (1999) 458-464.

34. E. Lugscheider, O. Knotek, K. Bobzin, S. Bärwulf, Tribological properties, phase generation and high temperature phase stability of tungsten- and vanadium-oxides deposited by reactive MSIP-PVD process for innovative lubrication applications, Surface and Coatings Technology 133-134 (2000) 362-368.

35. A. Banerji, S. Bhowmick, A.T. Alpas, High temperature tribological behavior of $\mathrm{W}$ containing diamond-like carbon (DLC) coating against titanium alloys, Surface and Coatings Technology 241 (2014) 93-104.

36. W. Gulbiński, T. Suszko, Thin films of $\mathrm{Mo}_{2} \mathrm{~N} / \mathrm{Ag}$ nanocomposite - the structure, mechanical and tribological properties, Surface and Coatings Technology 201 (2006) 1469-1476.

37. T. Suszko, W. Gulbiński, J. Jagielski, $\mathrm{Mo}_{2} \mathrm{~N} / \mathrm{Cu}$ thin films - the structure, mechanical and tribological properties, Surface and Coatings Technology 200 (2006) 6288-6292.

38. C.P. Mulligan, T.A. Blanchet, D. Gall, $\mathrm{CrN}-\mathrm{Ag}$ nanocomposite coatings: Tribology at room temperature and during a temperature ramp, Surface and Coatings Technology 204 (2010) 1388-1394.

39. P. Basnyat, et al., Mechanical and tribological properties of CrAlN-Ag self-lubricating films, Surface and Coatings Technology 202 (2007) 1011-1016.

40. K. Kutschej, C. Mitterer, C.P. Mulligan, D. Gall, Hightemperature tribological behavior of $\mathrm{CrN}-\mathrm{Ag}$ self-lubricating coatings, Advanced Engineering Materials 8 (2006) 1125-1129.

41. S.M. Aouadi, et al., Tribological investigation of adaptive $\mathrm{Mo}_{2} \mathrm{~N} / \mathrm{MoS}_{2} / \mathrm{Ag}$ coatings with high sulfur content, Surface and Coatings Technology 203 (2009) 1304-1309.

42. W. Zhang, D. Demydov, M.P. Jahan, K. Mistry, A. Erdemir, A.P. Malshe, Fundamental understanding of the tribological and thermal behavior of $\mathrm{Ag}-\mathrm{MoS}_{2}$ nanoparticle-based multicomponent lubricating system, Wear 288 (2012) 9-16.

43. S.V. Prasad, N.T. McDevitt, J.S. Zabinski, Tribology of tungsten disulfide-nanocrystalline zinc oxide adaptive lubricant films from ambient to $500{ }^{\circ} \mathrm{C}$, Wear 237 (2000) 186-196.

44. J.S. Zabinski, M.S. Donley, N.T. McDevitt, Mechanistic study of the synergism between $\mathrm{Sb}_{2} \mathrm{O}_{3}$ and $\mathrm{MoS}_{2}$ lubricant systems using Raman spectroscopy, Wear 165 (1993) 103-108.

45. J.S. Zabinski, M.S. Donley, V.J. Dyhouse, N.T. McDevitt, Chemical and tribological characterization of $\mathrm{PbO} / \mathrm{MoS}_{2}$ films grown by pulsed laser deposition, Thin Solid Films 214 (1992) $156-163$.

46. X.T. Zeng, TiN/NbN superlattice hard coatings deposited by unbalanced magnetron sputtering, Surface and Coatings Technology 113 (1999) 75-79.

47. M. Halvarsson, J.E. Trancik, S. Ruppi, The microstructure of CVD $\kappa-\mathrm{Al}_{2} \mathrm{O}_{3}$ multilayers separated by thin intermediate TiN or TiC layers, International Journal of Refractory Metals and Hard Materials 24 (2006) 32-38.

48. C. Muratore, J.J. Hu, A.A. Voevodin, Tribological coatings for lubrication over multiple thermal cycles, Surface and Coatings Technology 203 (2009) 957-962.

49. A.A. Voevodin, T.A. Fitz, J.J. Hu, J.S. Zabinski, Nanocomposite tribological coatings with "chameleon" surface adaptation, Journal of Vacuum Science \& Technology A 20 (2002) 1434-1444.

50. A.A. Voevodin, J.S. Zabinski, Supertough wear-resistant coatings with "chameleon" surface adaptation, Thin Solid Films 370 (2000) 223-231.

51. H. Paschke, M. Stueber, C. Ziebert, M. Bistron, P. Mayrhofer, Composition, microstructure and mechanical properties of boron containing multilayer coatings for hot forming tools, Surface and Coatings Technology 205 (2011) S24-S28. 
52. T. Bell, H. Dong, Y. Sun, Realising the potential of duplex surface engineering, Tribology International 31 (1998) 127-137.

53. A.A. Voevodin, J.S. Zabinski, Laser surface texturing for adaptive solid lubrication, Wear 261 (2006) 1285-1292.

54. X. Wang, K. Adachi, K. Otsuka, K. Kato, Optimization of the surface texture for silicon carbide sliding in water, Applied Surface Science 253 (2006) 1282-1286.

55. J.E. Krzanowski, J.L. Endrino, K. Hirschman, Novel composite coatings with $3 \mathrm{D}$ coating architectures for tribological applications fabricated using semiconductor patterning processes 203 (2002) 273-278.

56. P. Basnyat, et al., Surface texturing for adaptive solid lubrication, Surface and Coatings Technology 203 (2008) 73-79.

57. B. Luster, et al., Textured $\mathrm{VN}$ coatings with $\mathrm{Ag}_{3} \mathrm{VO}_{4}$ solid lubricant reservoirs, Surface and Coatings Technology 206 (2011) 1932-1935.

58. A. Moshkovith, V. Perfiliev, D. Gindin, N. Parkansky, R. Boxman, L. Rapoport, Surface texturing using pulsed air arc treatment, Wear 263 (2007) 1467-1469.
59. J.H. Zimmerman, C.G. Guleryuz, J.E. Krzanowski, Fabrication and tribological properties of titanium nitride coatings incorporating solid lubricant microreservoirs, Surface and Coatings Technology, 202 (2008) 2023-2032.

60. P.L. Dickrell, et al., Tunable friction behavior of oriented carbon nanotube films, Tribology Letters, 24 (2006) 85-90.

61. X. Zhang, et al., Carbon nanotube-MoS 2 composites as solid lubricants, ACS Applied Materials and Interfaces 1 (2009) 735-739.

62. A.H. Church, X.F. Zhang, B. Sirsota, P. Kohli, S.M. Aouadi, S. Talapatra, Carbon nanotube-based adaptive solid lubricant composites, Advanced Science Letters 5 (2012) 188-191.

63. D. Golberg, et al., Direct force measurements and kinking under elastic deformation of individual multiwalled boron nitride nanotubes, Nano Letters 7 (2007) 2146-2151.

64. B. Podgornik, S. Hogmark, O. Sandberg, Proper coating selection for improved galling performance of forming tool steel, Wear 261 (2006) 15-21.

Cite this article as: Zhang Z \& Dong H: A State-of-the-art overview. Manufacturing Rev. 2014, 1, 24. 